\title{
Differenz
}

Revista internacional de estudios heideggerianos y sus derivas contemporáneas

AÑO 3 NÚMERO 2: JULIO DE 2016. e-ISSN: 2386-4877 - DOI: 10.12795/DIFFERENZ.2016.I02.17

[pp. 269-271]

\section{HEIDEGGER, M. (2015): Construir, habitar, pensar. Barcelona: Oficina de Arte y Ediciones. 88 pp. Trad. Jesús Adrián Escudero.}

\section{Miguel Martín Cabeza}

Universidad de Sevilla (US)

La construcción y el ser humano han mantenido una relación íntima a lo largo de su evolución. Construimos para tener parques, unas vías transporte, colegios, mercados, un hogar... En definitiva construimos para vivir, para habitar. Ahora bien, ¿hasta qué punto podemos aceptar esto? ¿Es el construir un prerrequisito para el habitar? De hecho, ¿qué es el habitar? ¿Y el construir? ¿Acaso son lo mismo? Heidegger en la conferencia con el título Construir, habitar, pensar rompe con el pensamiento plano, mecanicista y técnico sobre la construcción y su relación con el vivir del ser humano, con el habitar en el que de suyo se encuentra. La presente edición impresa de la conferencia consta de tres partes: una cuidada edición bilingüe del texto de Heidegger a cargo de Arturo Leyte Coello y Jesús Adrián Escudero, el texto Habitar el desarraigo de Jesús Adrián y el texto Lo inhabitable de Arturo Leyte. Todo ello enlazado con una especial selección de fotografías por parte de Luis Asín en relación al texto principal. El libro en cuestión brilla por su brevedad y simpleza temática, la cual queda ampliamente resaltada por la situación contemporánea a la enfrentada en la conferencia de Heidegger, de la cual toma título.

Nos encontramos en agosto de 1951, Darmstadt, Alemania, la guerra ha acabado y la ciudad se encuentra arrasada, el casco antiguo destruido, la población en estado de supervivencia y todo ello acrecentado por la crisis de la falta de viviendas. En mitad de esta situación surge la nombrada conferencia como un lugar de reunión de arquitectos, arquitectos, empresarios... Heidegger desconcierta a los asistentes cuando el tema a 
tratar no es la planificación urbana sino más bien una problemática de índole filosófica. Y es que, para él, la construcción como un simple mecanismo de producción es un problema en sí mismo, la recién guerra no es más que un momento propio para la comprensión de una crisis que se arrastraba tiempo atrás. En primer lugar Heidegger trata el tema del habitar, ¿de qué se trata? ¿Por qué tomamos el construir y el habitar bajo un modelo de fin y medio? Los tratamos de forma separada cuando construir conlleva habitar. Una de las muestras de Heidegger hace uso de (como en tantas ocasiones) un extenso análisis etimológico. En resumen, la palabra bauen (construir) conllevaba el significado de erigir edificios (aedificare) así como el de proteger y cuidar (colere), este doble significado fue ocultado bajo el velo de lo habitual dando por hecho el cuidar y dejándolo en el olvido con el paso del tiempo. De modo que no sólo son la misma cosa sino que el cuidar resulta ser el rasgo fundamental de este habitar. Ahora bien, ¿qué hay que cuidar y proteger? Hay que cuidar las cosas precisamente porque permanecemos con ellas a lo largo de nuestra mortalidad. De modo que el habitar como un permanecer, un cuidar las cosas resulta ser un construir diferente al sentido estricto de edificar. En esta vertiente Heidegger introduce el término de la cuaternidad como modo de ver las cosas más allá de su carácter técnico y mecánico.

Heidegger expone el ejemplo del puente para ilustrar aquello que hemos nombrado como cuaternidad. Y es que el puente resulta ser un ejemplo intuitivo para la comprensión de este concepto debido a la complejidad que esconde su simple cruzar. Se trata de una estructura que nos permite cruzar de una orilla a otra, que protege ante el posible peligro del agua mientras que peligramos por el mero vértigo y, en mitad de esas circunstancias, allí nos encontramos, cruzándolo, es algo análogo a la vida. El puente en tanto es cosa reúne la cuaternidad en tanto nos permite verlo más que como un simple puente, algo técnico y mecánico, una sustancia. Y aunque nuestro pensamiento haya estado habituado a restar importancia a las cosas, ante el puente es capaz de recuperar ese interés, ese cuidado - hacia. Es más, el puente en tanto que reúne la cuaternidad es un lugar que está relacionado conmigo, con mí habitar, forma parte de él. No hablamos de un mero espacio analítico en el que se ha colocado un puente, es un lugar y lo es en tanto existe el puente. Esta visión es la que tanto se alejaba de los asistentes a la conferencia en tanto que para ellos era un problema de números y geometría, mientras que se trataba de una crisis anterior a la propia guerra. Antes de construir apropiadamente hay que reflexionar acerca de lo que es el propio habitar. Mientras el hombre trate desesperadamente de alcanzar una esencia estable del habitar mediante la técnica más lejos estará de comprender la inestabilidad del mismo. El desarraigo natural del ser humano reluce ante una guerra ya que todo aquello que parecía estable se desmorona del mismo modo que 
el vértigo que olvidamos al cruzar un puente resurge cuando nos asomamos al abismo. Heidegger reclama la necesidad de enfrentar el verdadero problema que es la necesidad de aprender a habitar, pensar desde el desarraigo para no olvidar el vértigo que de sí porta la vida y no por ello contiene menor valor, ni mucho menos.

Tras el texto principal de la conferencia de Heidegger encontramos los textos complementarios: Habitar el desarraigo y Lo inhabitable. Estos textos hacen especial referencias a la situación contemporánea a la conferencia a tratar ya que, como hemos comentado, la situación de postguerra es de gran importancia e idoneidad para la problemática tratada. Ambos resultan gran apoyo a la par que complemento para la conferencia, tanto por el resumen de las ideas en esta mencionadas como por el desarrollo más extenso de las mismas. Por un lado, Habitar el desarraigo amplia en gran medida las ideas mencionadas en la conferencia haciendo especial énfasis en el desarraigo. Todo ello bajo un punto de vista crítico hacia la sociedad técnica occidental, aquello a lo que Heidegger denomina Gestell (engranaje). Por otro lado, Lo inhabitable trata la pérdida de lo naturalmente habitable resaltado por la destrucción. Muestra como un evento tan catastrófico, prácticamente apocalíptico, reconduce al completo lo habitable. La catástrofe ha dejado una cicatriz en la estabilidad humana insoldable, ¿con qué seguridad habría de pensar en el hogar tras la creación de la bomba atómica? Tales obstáculos son capaces de destruir el habitar impropio, dejando en una fría nada. El texto muestra como aprender a habitar desde el desarraigo, el tránsito, torna en una necesidad ante tales hechos.

Nos encontramos ante un libro breve y no por ello menos importante ya que trata un tema de gran importancia para el ser humano tal como el habitar, que ha caído en el olvido, en la obviedad, en lo impropio... Este habitar, este vivir en relación con las cosas, suele quedar reducido a una mirada plana, olvidadiza e irreflexiva. En cambio, hay ocasiones en las que ese vértigo inherente que conlleva la vida resurge por capricho de las circunstancias. Es entonces cuando, como piedra lanzada cuyas ondas en el agua rompen el reflejo, somos capaces de romper con la mirada plana y tratar de comprender más allá de esta, de forma propia. En su momento, la idea de Heidegger fue tan inesperada como idónea por la fuerza del evento acontecido, incluso la mirada más plana e irreflexiva debía de ser perturbada por tal estruendo y, con ello, capaz de dar paso a un pensamiento más reflexivo. En definitiva, si alguno de los asistentes o lectores ha cuidado de su pensamiento al cruzar un puente habrá valido la pena la lectura. 